Article

\title{
Endophytic Colonization of Pepper (Capsicum annum) Controls Aphids (Myzus persicae Sulzer)
}

\author{
Spiridon Mantzoukas ${ }^{1,2, *}$ and Ioannis Lagogiannis ${ }^{1,2}$ \\ 1 Department of Pharmacy, School of Health Sciences, University of Patras, 26504 Patras, Greece; \\ lagoipp@gmail.com \\ 2 ELGO-Demeter, Plant Protection Division of Patras, NEO \& L. Amerikis, 26444 Patras, Greece \\ * Correspondence: sdmantzoukas1979@gmail.com
}

Received: 17 March 2019; Accepted: 22 April 2019; Published: 30 May 2019

\begin{abstract}
Aphids are among the most harmful crop pests, damaging plants by sucking sap or by transmitting pathogenic viruses. Plant infestation by aphids depends on their population growth. Entomopathogenic fungi are essential participants of terrestrial and aquatic ecosystems, regulating arthropod communities. Many fungal species with a symbiotic-endophytic relation with plants are pathogenic, producing insecticides or insect repellents. The present study investigated the effects of the fungal entomopathogens Beauveria bassiana, Metarhizium anisopliae and Isaria fumosorosea, following their endophytic colonization of the sweet pepper Capsicum annum, on the development of the green peach aphid Myzus persicae. After 21 days, B. bassiana produced 100\% aphid mortality, M. anisopliae 90\% and I. fumosorosea $83.3 \%$. There were also significant differences in terms of the effect on aphid population in planta and on the survival time of young adults in planta. External mycelium appeared within $96 \mathrm{~h}$ after placing aphid cadavers on damp filter paper. PCR confirmed that the mycelium was of B. bassiana, M. anisopliae and I. fumosorosea. DNA sequences collected from this work were matched with existing sequences data in GenBank, using the Basic Local Alignment Search Tool. Our results showed that none of the three fungal isolates had an effect in promoting or suppressing the growth of C. annum.
\end{abstract}

Keywords: Myzus persicae; endophytic; control; Capsicum annum

\section{Introduction}

Endophytes are microorganisms that spend at least part of their lives living non-parasitically within plants [1]. There is accumulated evidence that many entomopathogenic fungi are symbiotic with several plant species while others are species-specific. Usually, this endophytic relationship reinforces plants with insecticidal or insect repellent traits, a characteristic that could be exploited for designing environmentally friendly applications for insect control in agriculture [1,2]. Fungal entomopathogens such as Beauveria bassiana Balsamo (Vuillemin) (Hypocreales: Cordycipitaceae), Metarhizium anisopliae (Metchnikoff) Sorokin (Hypocreales: Clavicipitaceae) and Isaria fumosorosea (Wize) Brown \& Smith (Hypocreales: Clavicipitaceae), are important participants in the regulation of pest populations.

There is a plethora of recent studies on the insecticidal and insect-repellent attributes of endophytic entomopathogenic fungi [1,3-7]. In fact, as well as being potentially beneficial to plant growth [3], they are also capable of increasing rates of infection and mortality among feeding insects, compared to other biological agents. Noteworthy is also the fact that their symbiosis with the host plant is usually asymptomatic while it triggers the plant to adjust its response to abiotic changes [8-11]. Endophytic entomopathogenic fungi are thus considered as a promising alternative for chemical insecticides and transgenic plants [12]. Aphids are important plant pests, causing considerable direct or indirect losses to several crop species [13]. 
The green peach aphid Myzus persicae Sulzer (Homoptera: Aphididae) is a cosmopolitan aphid species responsible for serious economic losses. It is polyphagous, feeding on more than 50 plant families, damaging agricultural, industrial and horticultural crops, as well as stone fruits. In Greece, M. persicae is an important pest in pepper crops [14], and aphid control is predominantly achieved with chemical insecticides. However, this practice has caused environmental and resistance problems [14]. Consequently, there is an increasing interest in the use of endophytic entomopathogenic fungi in biological plant protection. In this context, we documented the effects of the endophytic B. bassiana, M. anisopliae and I. fumosorosea, in the sweet pepper Capsicum annum, on the development of the green peach aphid Myzus persicae. To this end, we sprayed the pepper plant with $10^{8}$ conidia/mL of each fungus. Aphid mortality, aphid population and plant growth parameters were monitored and recorded for three months.

\section{Materials and Methods}

\subsection{Fungi, Insect and Plant Material}

Local fungal strains of B. bassiana (strain name: GBBSTTS), I. fumosorosea (strain name: RHZ4RAS) and M. anisopliae (strain name: Z3RAS) from the Achaia region, Greece, were used. Soil samples were collected from random regions in the prefecture of Achaia. We chose to retrieve fungi from their natural habitat, as opposed to using laboratory strains, as the former are expected to have higher endophytic ability. To collect the soil samples, the surface litter was removed, and the soil was dug to a depth of $10 \mathrm{~cm}$ with a soil core borer. The samples, which weighed $300 \mathrm{~g}$ each, were placed in plastic bags and stored at $4{ }^{\circ} \mathrm{C}$ until they were transferred to the laboratory for further processing. As the fungi contained in the soil samples would later be retrieved using 3rd-instar Galleria mellonella L. larvae (Lepidoptera: Pyralidae) as baits, the collected soil was placed on rough cardboard on the laboratory stalls for $24 \mathrm{~h}$ to reduce its humidity. This was necessary as in conditions of excess humidity, the entomopathogenic nematodes present in the soil would attack and kill the larvae of the insect bait before the entomopathogenic fungi [15].

Once the soil was dry, it was sieved and placed in petri dishes (10 $\mathrm{g}$ of soil from each soil sample) where $10 \mathrm{G}$. mellonella larvae were also inserted. This was repeated three times (every 10 days), meaning that by the end of the experiment, $30 \mathrm{G}$. mellonella individuals were tested in total per soil sample. The G. mellonella individuals were kindly provided by the Benaki Phytopathological Institute, Athens. Once in the petri dishes, the G. mellonella individuals were left in special dark chambers at a temperature of $25 \pm 1{ }^{\circ} \mathrm{C}$ for 14 days. Those insects which exhibited fungal infection were then isolated in different petri dishes on a layer of the nutrient Sabouraud dextrose agar or SDA (Sabouraud Dextrose Agar, OXOID LTD). Alternatively, fungal conidia which had been removed from the infected insects, were cultivated on the same material. Conidia were required to prepare fungal solutions which would later be sprayed on the pepper plants. The petri dishes were kept at a temperature of $25 \pm 1{ }^{\circ} \mathrm{C}$ in the dark, to achieve the incubation and development of the fungi. When a fungus developed, it was isolated once more in order to avoid infestation and to obtain a pure fungal colony. This was achieved by subculturing of the fungal hyphae. Isolates were maintained in petri dishes on a nutrient SDA material at $25 \pm 1{ }^{\circ} \mathrm{C}$ and were renewed every month for the duration of the experiment. Fifteen days after the pure colony was last isolated, fresh conidia were collected from the SDA cultures and transferred to a $500 \mathrm{~mL}$ glass beaker with $100 \mathrm{~mL}$ sterile distilled water containing $0.05 \%$ Tergitol NP9. The conidial suspension was filtered across 10-12 layers of sterile cloth to remove hyphal debris and prepared for the spraying of pepper plants by mixing the solution with a magnetic stirrer for $5 \mathrm{~min}$ [16]. Suspensions were adjusted at $1 \times 10^{8}$ conidia per milliliter according to Gurulingappa et al. [17], using a Neubauer hemocytometer (TIEFE 0,100 $\mathrm{mm} \mathrm{1/400} 9 \mathrm{~mm}$ ). The viability of conidia, which was over $95 \%$ in all cases, was determined after $24 \mathrm{~h}$ by repeating a germination test for each stock suspension as described by Goettel and Inglis [15], in order to ensure the constancy of the viability assessments. 
The colony of the aphids (collected from greenhouse pepper plants) was kept on pepper plants in a growth chamber (PHC Europe/Sanyo/Panasonic Biomedical MLR-352-PE), in controlled environmental conditions $\left(27 \pm 1{ }^{\circ} \mathrm{C}, 65 \pm 5 \%\right.$ r.h., $16: 8$ light-night) throughout their biological cycle.

We used the pepper plant variety Stauros Peloponnesus (Capsicum annum L. Solanales: Solanaceae). The pepper plants were pre-germinated in $2 \times 2 \mathrm{~cm}$ pots (one seed per pot in a depth of about $1 \mathrm{~cm}$ ), filled with manufactured peat substrate (Pindstrup Plus ${ }^{\mathrm{TM}}$ ). The plants were then transplanted into $1 \mathrm{~L}$ pots, using the same peat substrate. The plants were kept in a growth chamber $\left(27 \pm 1{ }^{\circ} \mathrm{C}, 65 \pm 5 \%\right.$ r.h., complete darkness) for the first $24 \mathrm{~h}$. They were then kept in the same growth chamber for the duration of the experiment in $27 \pm 1{ }^{\circ} \mathrm{C}, 65 \pm 5 \%$ r.h and 16:8 light-night. The plants were only administered water $(200 \mathrm{~mL})$ every three days.

\subsection{Plant Inoculation with Fungal Entomopathogens and Assessment of Endophytic Colonization}

To investigate the presence of endophytic-stage entomopathogenic fungi, randomized C. annum leaves were collected with sterile scissors from same age plants, seven days after spraying them (foliar method) with fungal conidia $\left(1 \times 10^{8}\right.$ conidia/mL). Samples of pepper leaves were cut into $1 \mathrm{~cm}$ diameter and $0.5 \mathrm{~cm}$ thick discs in a laminar flow chamber. The samples were surface sterilized by immersion in $96 \%$ ethanol solution for one minute, in $6 \%$ sodium hypochlorite solution for five minutes and finally, in $96 \%$ ethanol solution for $30 \mathrm{~s}$ [2]. Sterile leaf samples were then inoculated into SDA substrate using a sterile metal hook. The cultures on the SDA substrate samples were incubated in the dark at $25{ }^{\circ} \mathrm{C} \pm 2$ and $80 \%$ humidity. The growth of conidia lasted 14 days. The germination of fungal conidia on the pepper leaves was evaluated using an optical microscope $(40 \times)$. The number of leaves displaying fungal growth was calculated using the following formula: Number of pepper leaves with fungal growth/total number of samples $[2,18]$. For each fungus, eight samples from different areas of the leaf were taken, which were then placed on the SDA growth substrate and grown in the dark at $25{ }^{\circ} \mathrm{C} \pm 2$ and in $80 \%$ humidity. At the end of the experiment, we measured the height of the pepper plants (distance from the ground to the apical part of the stem) and counted the leaves. Experiments were performed during a period of approximately three months and the duration was 21 days each.

\subsection{Effect of Endophytic Entomopathogenic Fungi on M. persicae}

When pepper plants reached the four-leaf stage, they were sprayed (foliar method) until dripping $[2,18]$. Sterile sprayers were used for each entomopathogenic microorganism and conidial suspensions were at $10^{8}$ conidia/mL. After spraying with the fungal suspensions, the plants were covered for $24 \mathrm{~h}$ with large diameter black bags to maintain high moisture on the surface of the plant [2]. After $24 \mathrm{~h}, 10$ apterous M. persicae aphids were placed on a randomized leaf after one-hour starvation. Ten aphids were used per treatment $(n=10)$, and each experiment $(n=40)$ was replicated three times $(n=120)$. We used a well-developed pepper leaf for each of the three treatments and one for the control, in a block design with four blocks. Each block therefore consisted of three treatments plus the control which were replicated three times, thus producing a total of 48 plants for the entire experiment. The leaf with the aphids was placed in an organdie $10 \times 30$ cage, to prevent dispersion into the experiment area. The aphid population was recorded on a weekly basis. The experiments were performed during a period of approximately three months and the duration was 21 days each.

\subsection{Determining the Cause of Death of M. persicae}

The DNA sequencing process was also applied to determine the cause of death of aphids, adopting the method outlined by Rogers and Bendich [19]. The genomic DNA (gDNA) was extracted by applying universal primer sets ITS4 (5'-TCCTCCGCTTATTGATATGC- $\left.3^{\prime}\right)$ and ITS5 (5'-GGAAGTAAAAGTCGTAAC AAGG-3'); a fragment of the internal transcribed spacer (ITS) region was amplified. PCR reactions $(30 \mu \mathrm{L})$ included $50 \mathrm{ng}$ of template gDNA, $1.25 \mu \mathrm{L}$ of each $10 \mathrm{pM}$ oligonucleotide, $1 \mu \mathrm{L}$ of $10 \mathrm{mM}$ deoxyribonucleotide triphosphates (dNTPs), $1 \mu \mathrm{L}$ of $2 \mathrm{U} / \mu \mathrm{L}$ Taq DNA polymerase (Minotech), $1.5 \mu \mathrm{L}$ of $\mathrm{MgCl}_{2}$, and $2.5 \mu \mathrm{L}$ of $10 \times \mathrm{PCR}$ buffer. The PCR protocol for 
amplification of the ITS regions included 31 cycles at $94{ }^{\circ} \mathrm{C}$ for $60 \mathrm{~s}$, at $55{ }^{\circ} \mathrm{C}$ for $60 \mathrm{~s}$, and at $72{ }^{\circ} \mathrm{C}$ for $90 \mathrm{~s}$, followed by a final elongation at $72{ }^{\circ} \mathrm{C}$ for $5 \mathrm{~min}$. PCR products were kept at $4{ }^{\circ} \mathrm{C}$. The quantity and quality of PCR products was resolved by gel electrophoresis, using $2 \%$ agarose gel stained with SYBR Safe DNA Gel Stain (Invitrogen), and visualized under UV light (BIO RAD, Bio-Rad Laboratories M.EPE Greece, Molecular Imager Gel Doc XR System). The amplified products were purified and sequenced in CeMIA SA, University of Thessaly.

\subsection{Statistical Analysis}

All statistical analyses were conducted using SPSS v.23 (IBM-SPSS Statistics, Armonk, NY, USA). For growth measurements, colonization percentage, mortality and population, one-way ANOVA was performed. Bonferroni's post-hoc test was used to compare means of treatments. The Kaplan-Meier method was selected to determine the mean overall survival, proportion terminating, proportion surviving, cumulative proportion surviving at end of the experiment, and the hazard rate of treated vs. untreated plants on aphids. Corrected percent mortality was calculated using Abbott's formula [20]. All values were arcsine transformed prior to analysis.

The mathematical expression of Abbott's formula is:

$$
\begin{aligned}
\text { Corrected } \% & =(1-\mathrm{n} \text { in } \mathrm{T} \text { after treatment } / \mathrm{n} \text { in Co after treatment }) * 100, \\
\mathrm{n} & =\text { insect population, } \mathrm{T}=\text { treated, } \mathrm{Co}=\text { control. }
\end{aligned}
$$

Comparison of survival distributions was obtained using Breslow (Generalized Wilcoxon) (SPSS v.23.0). Survival data are often described and input in terms of survival probability and hazard probability. The former, $\mathrm{S}(\mathrm{t})$, refers to the probability that an individual has of surviving an event from the beginning to a specified point in time, $t$. Hazard probability, $h(t)$ or $\lambda(t)$, refers to the probability that an individual, who is under observation at a specific time $t$, will experience an event at that time $t$. The Cox model is mathematically expressed as:

$$
h(t)=h 0(t) \times \exp \{b 1 x 1+b 2 \times 2+\ldots+b p x p\},
$$

whereby $h(t)$ is produced by the covariates $(x 1, x 2, \ldots, x p)$ and the size of their coefficients $(b 1, b 2, \ldots$, $\mathrm{bp})$. Hazard probability is very likely to vary over time. The value of baseline hazard, h0, is zero.

\section{Results}

\subsection{Re-Isolation of Endophytic Entomopathogenic Fungi from Pepper Leaves on SDA Substrate}

To prove endophytic colonization of pepper leaves by M. anisopliae, B. bassiana and I. fumosorosea, leaves of same age plants were sprayed with conidial suspensions at $10^{8}$ conidia/mL. Seven days post inoculation, leaves were cut and their surface sterilized. Subsequent growth of endophytic fungi on dextrose agar was monitored. Mycelium began to appear 6 days later and had developed completely after 11 days at $25^{\circ} \mathrm{C} \pm 2$ and $95 \%$ humidity. Successful re-isolations of the three fungi were obtained from both leaves and stems of plants of the corresponding treatments (Figures 1 and 2). Decline of colonization was observed after 14 days, in leaves of plants treated with endophytes $(\mathrm{F}=2.156, \mathrm{df}=2$, $70, p=0.133)$. 


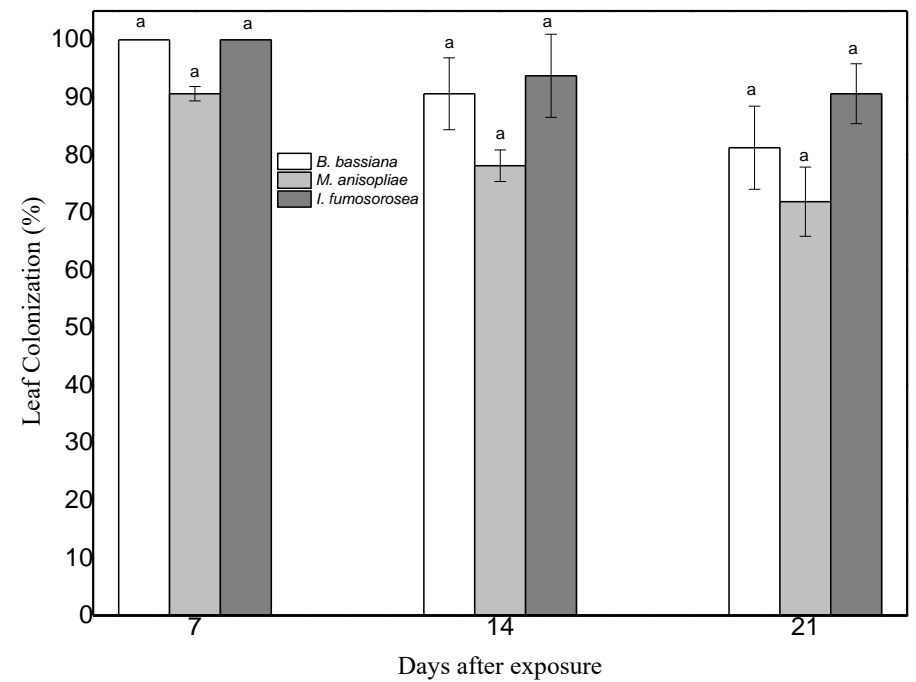

Figure 1. Mean ( \pm sd; $n=24$ ) surface colonization of same age C. annum leaf parts by B. bassiana, M. anisopliae and I. fumosorosea at 7 days, 14 days, and 21 days after exposure. Mean \pm sd values with the same superscript letter are not different in a significant way (Bonferroni's test: $p<0.05$ ).

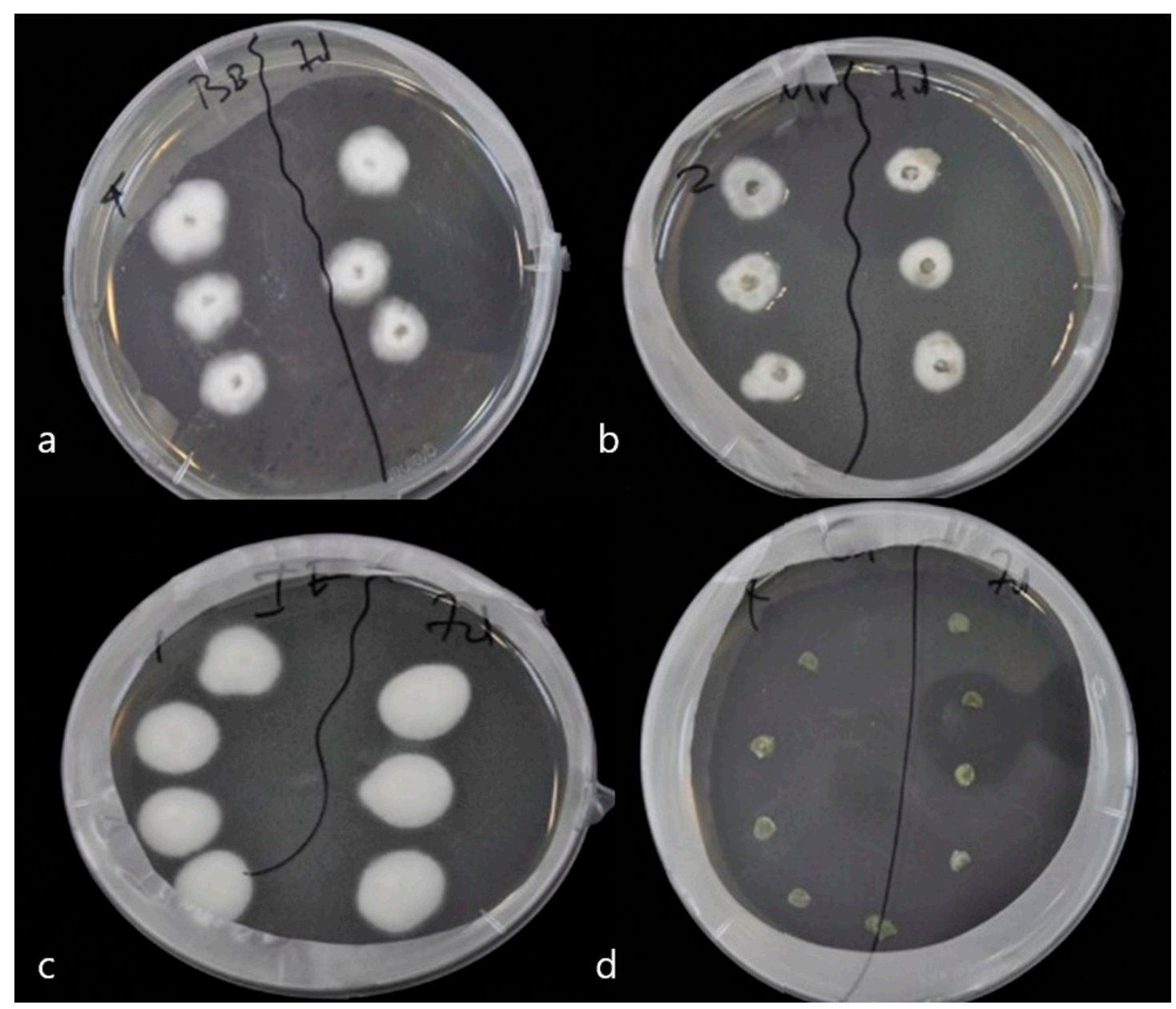

Figure 2. Detection of endophytic entomopathogenic fungi on treated and untreated pepper plants. The fungus was fully developed after 11 days, on Sabouraud dextrose agar. (a) B. bassiana, (b) M. anisopliae, (c) I. fumosorosea, and (d) Control. 


\subsection{Survival of M. persicae Aphids on Endophytically Colonized Pepper Plants}

To determine the effect of endophytes on the survival of $M$. persicae, pepper plants were sprayed with $10^{8}$ conidia/mL of each fungus. After $24 \mathrm{~h}$, apterous $M$. persicae aphids were placed on the plant, after they had been starved for one hour. Aphid population was monitored and recorded on a weekly basis. Experiments showed endophytic ability of the three fungi in the pepper plant. Moreover, colonized plants showed strong entomopathogenic activity against young adults of the $M$. persicae aphid. In terms of the average mortality, there are statistically significant differences between treatments. After 21 days, mortality was at $100 \%$ in plants colonized with B. bassiana, at $90 \%$ in plants colonized with M. anisopliae, at $83.3 \%$ in plants colonized with I. fumosorosea, while the control plants showed $0 \%(\mathrm{~F}=6.475, \mathrm{df}=6.35, p<0.001)$ (Figure 3$)$. In terms of the average change in aphid population at the end of the experiment, there were statistically significant differences between treatments; after 21 days, there were $0.7 \pm 1.2$ aphids for endophytic B. bassiana, $6.7 \pm 3.2$ aphids for endophytic $M$. anisopliae, and $6.7 \pm 2.1$ aphids for endophytic I. fumosorosea, while in the control plants the aphid population was $\left(\mathrm{H}_{2} \mathrm{O}+\right.$ Tergitol NP9 $\left.0.05 \%\right) 68 \pm 13.8$ aphids $(\mathrm{F}=6.475, \mathrm{df}=6.35, p<0.001)$ (Figure 4). All plants colonized with endophytic entomopathogenic fungi had a significant effect on the aphid population in planta $(\mathrm{F}=26.802, \mathrm{df}=6.35, p<0.001)$ and on the survival time of the young apterous adults in planta (Wilcoxon Gehan test: 67.593, $\mathrm{df}=3, p<0.001$ ). The Kaplan-Meier survival analysis (Breslow (Generalized Wilcoxon)) determined the survival time of aphids on endophytically colonized plants. The average survival time was 13.18 days with B. bassiana, 18.08 days with M. anisopliae, 16.80 days with I. fumosorosea and 21.00 days in control plants. The average number of aphids covered by mycelium on the pepper leaf was $4.3 \pm 1.5$ at 7 DAE for B. bassiana, $2.3 \pm 1.5$ at 14 DAE for M. anisopliae and $1.7 \pm 0.7$ at 14 DAE for I. fumosorosea.

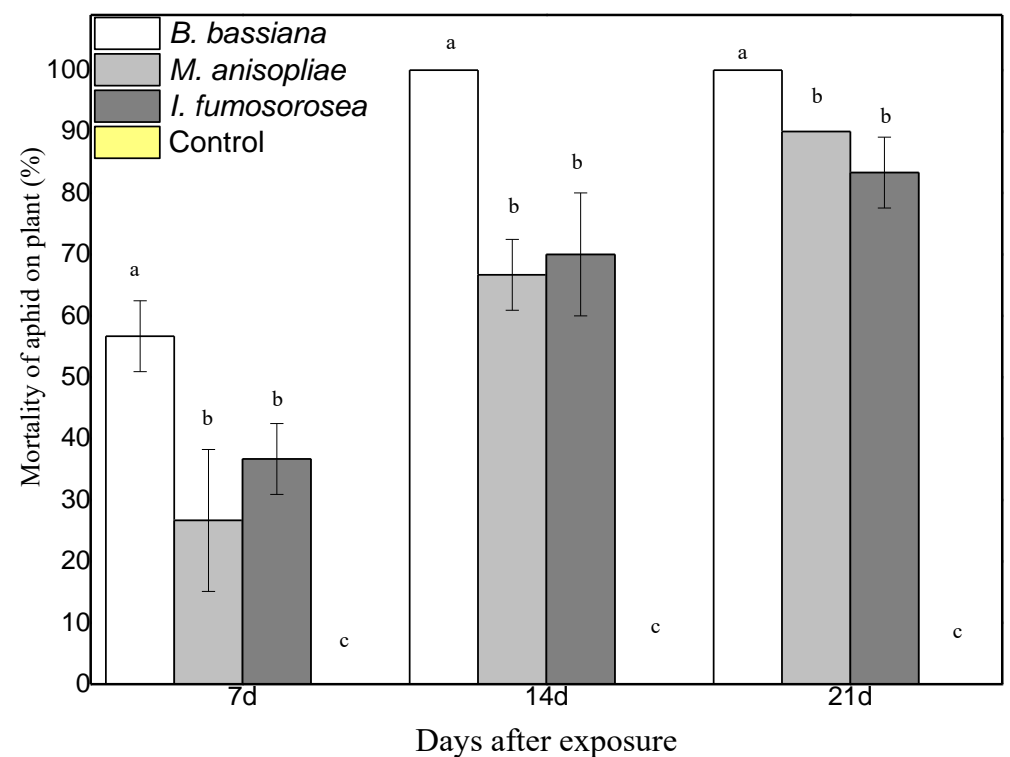

Figure 3. Mortality of M. persicae aphids on the leaves of endophytic plants, following exposure to endophytic entomopathogenic fungi after 7, 14 and 21 days. Mean \pm sd values with the same superscript letter are not different in a significant way. (Bonferroni's test: $p<0.05$ ).

The median lethal time $\left(\mathrm{LT}_{50}\right)$ calculated with the Kaplan-Meier survival analysis showed that the lethal time of aphids on pepper leaves was 7 DAE with B. bassiana, followed by I. fumosorosea at $14 \mathrm{DAE}$ and M. anisopliae at $14 \mathrm{DAE}$. The highest hazard rate on aphids was $14 \mathrm{DAE}$ in plants colonized with B. bassiana (Table 1). The hazard rate on aphids was 21 DAE in plants colonized with M. anisopliae and I. fumosorosea (Table 1). Finally, the proportion terminating of aphids in plants colonized with B. bassiana was $100 \%$ at $7 \mathrm{DAE}$, and their proportion surviving was $100 \%$ at $14 \mathrm{DAE}$. With M. anisopliae, the proportion terminating was $82 \%$ at $14 \mathrm{DAE}$ and the proportion surviving was $100 \%$ at $21 \mathrm{DAE}$. 
With I. fumosorosea, the proportion terminating was $62 \%$ at 14 DAE and the proportion surviving was $100 \%$ at 21 DAE (Table 1). In control plants, the proportion of surviving apterous adults was $100 \%$ for the duration of the experiment (Table 1). The cumulative proportion of insects surviving at the end of the experiment was $0 \%$ at 14 DAE with B. bassiana; $6 \%$ at 21 DAE with M. anisopliae; and $12 \%$ at 21 DAE with I. fumosorosea (Table 1). In control plants, the cumulative proportion of apterous adults surviving at the end of the experiment was 100\% (Table 1). Post-mortem mycelial and conidial growth demonstrated that almost all dead individuals had died due to pathogen virulence. Based on observations of aphid cadavers, the external mycelium appears within $96 \mathrm{~h}$ after placing them on damp filter paper. This was also confirmed by PCR. DNA sequences in this work were matched with existing sequences data in GenBank, working with the Basic Local Alignment Search Tool (NCBI BLAST).

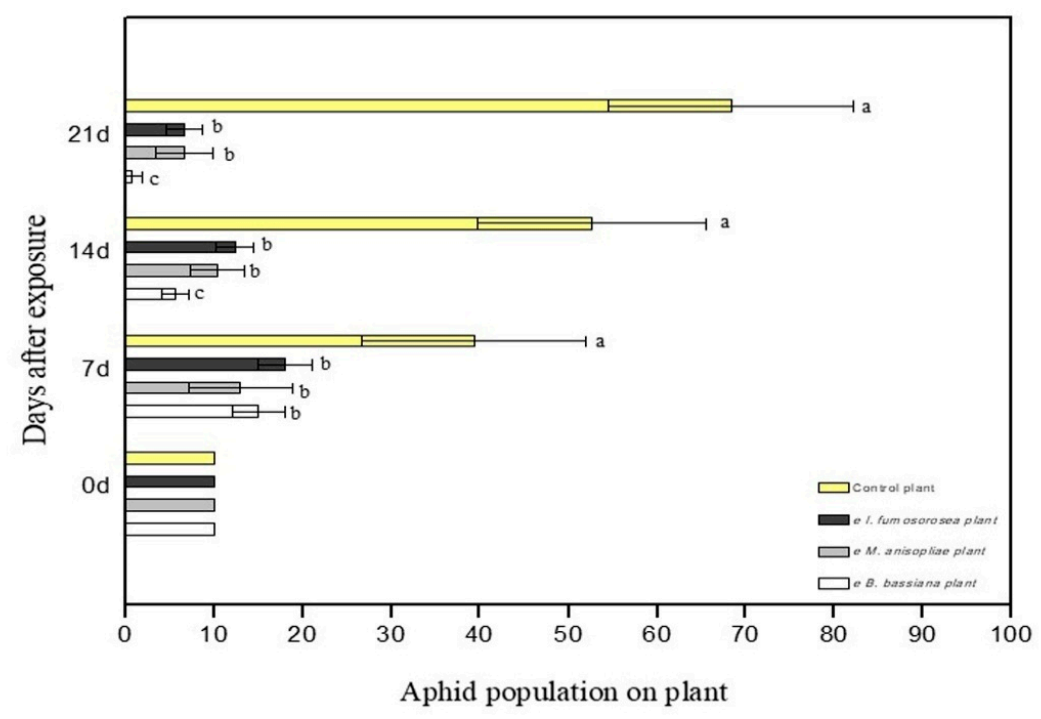

Figure 4. M. persicae aphid population on the leaves of C. annum plants after exposure to endophytic entomopathogenic fungi. Mean \pm sd values with the same superscript letter are not different in a significant way. (Bonferroni's test: $p<0.05$ ).

Table 1. Proportion terminating, proportion surviving, cumulative proportion surviving and hazard rate of endophytic colonized pepper plants on young apterous adults of the M. persicae aphid (Kaplan-Meier survival function, life table parameters).

\begin{tabular}{|c|c|c|c|c|c|}
\hline Treatment & $\begin{array}{l}\text { Day after } \\
\text { Exposure } \\
\text { (DAE) }\end{array}$ & $\begin{array}{c}\text { Proportion } \\
\text { Terminating * } \\
(\%)\end{array}$ & $\begin{array}{l}\text { Proportion } \\
\text { Surviving } * * \\
(\%)\end{array}$ & $\begin{array}{l}\text { Cumulative Proportion } \\
\text { Surviving at End of } \\
\text { Interval } * * *(\% \pm \mathrm{sd})\end{array}$ & $\begin{array}{l}\text { Hazard Rate } \\
* * * *(\% \pm \mathrm{sd})\end{array}$ \\
\hline \multirow{3}{*}{$\begin{array}{l}\text { B. bassiana } \\
\text { plants }\end{array}$} & 0 & 57 & 43 & 100 & 00 \\
\hline & 7 & 100 & 00 & $43 \pm 09$ & $11 \pm 03$ \\
\hline & 14 & 00 & 100 & 00 & 29 \\
\hline \multirow{4}{*}{$\begin{array}{l}\text { M. anisopliae } \\
\text { plants }\end{array}$} & 0 & 27 & 73 & 100 & 00 \\
\hline & 7 & 55 & 45 & $73 \pm 08$ & $04 \pm 02$ \\
\hline & 14 & 82 & 18 & $33 \pm 09$ & $11 \pm 03$ \\
\hline & 21 & 00 & 100 & $06 \pm 05$ & 00 \\
\hline \multirow{4}{*}{$\begin{array}{l}\text { I. fumosorosea } \\
\text { plants }\end{array}$} & 0 & 37 & 63 & 100 & 00 \\
\hline & 7 & 53 & 47 & $63 \pm 09$ & $06 \pm 02$ \\
\hline & 14 & 62 & 38 & $30 \pm 08$ & $10 \pm 03$ \\
\hline & 21 & 00 & 100 & $12 \pm 07$ & 00 \\
\hline \multirow{4}{*}{ Control plants } & 0 & 00 & 100 & 100 & 00 \\
\hline & 7 & 00 & 100 & 100 & 00 \\
\hline & 14 & 00 & 100 & 100 & 00 \\
\hline & 21 & 00 & 100 & 100 & 00 \\
\hline
\end{tabular}

* Proportion Terminating: The ratio of individuals surviving to the terminal event, to the number of individuals exposed to risk. ${ }^{* *}$ Proportion Surviving: One minus the proportion terminating. ${ }^{* *}$ Cumulative Proportion Surviving at End of Interval: The proportion of individuals surviving from the start of the experiment to the end of the interval. ${ }^{* * * *}$ Hazard Rate: An estimate of the risk of death during the interval. 


\subsection{Capsicum annum Growth (Height and Number of Leaves)}

At the end of the experiment, to establish whether endophytic colonization affected plant growth parameters, we measured the height of the pepper plants (distance from the ground to the apical part of the stem) and counted the leaves. The growth of pepper leaves ranged from $14 \mathrm{~cm}$ (Control) to $16.25 \mathrm{~cm}$ (I. fumosorosea) (Figure 5), and the plant heights from $14.75 \mathrm{~cm}$ (M. anisopliae) to $17 \mathrm{~cm}$ (Control) (Figure 5). From the above results, there are no statistically significant differences between plant heights $(\mathrm{F}=3.902, \mathrm{df}=3.23, p=0.240)$ or in the number of leaves between colonized plants $(\mathrm{F}=0.759, \mathrm{df}=3.23, p=0.530)$.

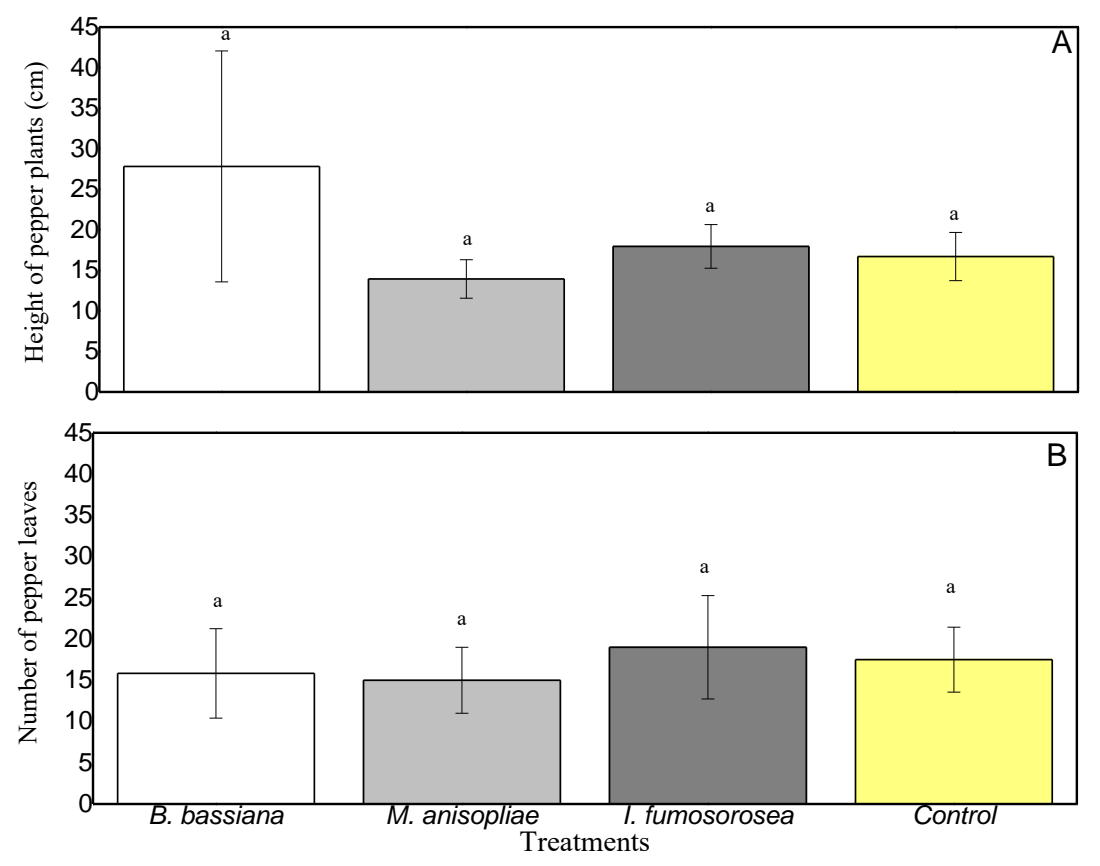

Figure 5. C. annum growth in terms of (A) height of pepper plants and (B) number of pepper leaves. Mean \pm sd values with the same superscript letter are not different in a significant way (Bonferroni's test: $p<0.05)$.

\section{Discussion}

Research indicates that biocontrol agents such as Beauveria, Metarhizium and Isaria generate systemic resistance against herbivorous insects [2,21,22]. A significant decrease in the population of M. persicae in endophytically colonized pepper plants was recorded in our experiment. Similar findings were reported by Akello and Sikora [23] for Aphis fabae (Hemiptera: Aphididae) and Pelizza et al. [24] for Dichroplus maculipennis (Orthoptera: Acrididae). The literature suggests that endophytic entomopathogenic fungi, particularly B. bassiana, induce plant defenses which, in turn, suppress insects. Analogous results were also observed for C. annum in this study.

Following research on different kinds of grass, endophytes seem to negatively affect herbivores through several mechanisms, ranging from antixenosis and/or antibiosis to the plant generating secondary compounds and/or to the endophytes producing secondary metabolites $[1,2,25]$. Infection by endophytes is conditional upon the genetic and environmental make-up of the insect population. The host plant's odor or taste comes from nutrients and odd compounds that are transformed into complex sensorial inputs in herbivore insects [26]. These inputs are interpreted by the insect's central nervous system to determine whether a given plant is a suitable host [13].

It is also assumed that endophytes modify the chemical profile of the plant by altering its phytosterol composition and that they compete with insects for nutritional compounds [27]. In positively colonized B. bassiana plants, the overall aphid population was decimated after 14 DAE. Similar results were obtained for the other colonized plants, with the reduction found to be significant compared with the 
aphid population in control plants. It is yet to be established how endophytic fungi may protect plants from insect herbivores. The production of secondary metabolites by endophytes is not necessarily the reason for the negative impact on the aphids which was observed in our study. These negative effects are evident in the high proportion of aphids terminating and the low proportion of aphids surviving in colonized plants, compared to the high proportion surviving in control plants. Moreover, cumulative proportion surviving at end of the interval in colonized plants was significantly lower compared to the control plants. The hazard rate of colonized plants was significantly higher, especially at $14 \mathrm{DAE}$, in comparison with control plants. Systemic spread was previously documented by Bing and Lewis [28], Wagner and Lewis [11], Posada and Vega [29,30], Gómez-Vidal et al. [31], Akello et al. [4], Tefera and Vidal [32], Arab and El-Deeb [33], Batta [34], Landa et al. [35], Mantzoukas et al. [2], Ramírez-Rodríguez and Sánchez-Peña [36,37], and Jaber and Araj [38]. In the current study, the plant displayed no obvious signs of disease after conidia had been sprayed onto the leaves. Viable conidia are known to adhere to the surface of the plant instead of floating in the solution, even after application of surfactants [32].

Aphids possess a simple body structure, whereby insects feed and reproduce efficiently, while the larger part of the nutrient intake is invested in the production of nymphs [36]. In studies published so far, mycosis has either not been tested or not observed in the endophytic phase of entomopathogenic fungi. Akello et al. [4] have reported mycosis of more than $60 \%$ of Cosmopolites sordidus (Coleoptera: Curculionidae) adults in their herbivore developmental stages, feeding on inoculated banana plants. Larvae of Helicoverpa zea (Lepidoptera: Noctuidae) in tomato plants [39], Helicoverpa armigera (Lepidoptera: Noctuidae) in faba plants [25] and D. maculipennis [24] have been reported as mycosed by endophytic B. bassiana, but not in all tested strains. Mycosis was not determined on Bemicia tabaci (Homoptera: Aleyrodidae) following exposure to endophytic fungal entomopathogens (B. bassiana strain NATURALIS and Metarhizium brunneum strain BIPESCO5) [38]. In our experiment, mycosis of aphids was found at 7 DAE for B. bassiana and at 14 DAE for M. anisopliae and I. fumosorosea.

Established endophytes should not normally influence the physiology and growth of the plant [40]. Occasionally, they may enhance host resistance to stressful environmental conditions [7], such as drought and lack of nutrients [6], or strengthen host defense against biotic threats [4,11,23,25]. Endophytic entomopathogenic fungi may enhance plant growth in a way which renders plants more resistant to insect herbivory and ensuing loss of biomass [8]. Posada and Vega [30] found that the presence of entomopathogenic fungi had a positive impact on all growth parameters of coffee seedlings, whereas Griffin et al. [41], Ownley et al. [42], and Ownley et al. [21] observed that B. bassiana in tomato and cotton plants contributed to a substantial increase in the height of these crops. Lopez and Sword [43] noted that inoculation with B. bassiana and Purpureocillium lilacinum (Thom) Samson (Hypocreales: Ophiocordycipitaceae) produced an enhancement of certain growth parameters in cotton plants, such as dry weight and size of the reproductive structures. Greenfield et al. [44] observed increased growth of cassava plants, post-inoculation with B. bassiana and M. anisopliae. Qayyum et al. [45], who inoculated two different strains of $B$. bassiana in tomato plants, noted that one strain favored plant growth while the other delayed plant growth and development and caused a reduction in the size of the fruits. B. bassiana benefited all growth parameters of Glycine max (L.) Merr. [40]. Our results indicate that the three fungal isolates used in this study had no role in suppressing or promoting the growth of $C$. annum under the conditions tested. However, further research is required to discover the mechanisms by which these fungi manage to regulate aphid populations. Such studies are crucial in evaluating the potential of non-chemical alternatives for pest management in peppers, as this information has previously been unavailable. Moreover, as the use of endophytes is a pioneering research field, more studies need to be pursued on the applicability of spraying fungal conidia on pepper plants, especially in field conditions.

\section{Conclusions}

In conclusion, our experiment demonstrates that that application of conidia of fungal endophytes - that are known to infect pepper plants—affect aphid populations by causing feeding disorders or disruption of the aphid reproduction cycle. Compared to the control, plant treatment with 
endophytic entomopathogenic fungi lowered the aphid population, but this effect was conditional upon the isolate; these isolates present a wide range of activity which can be utilized in the biological control of M. persicae. Our findings support the notion that botanical and microbial pesticides, either separately or in conjunction with chemicals and other options, can provide effective pest control.

Author Contributions: Conceptualization, S.M.; Methodology, S.M.; Software, S.M.; Validation, S.M. and I.L.; Formal Analysis, S.M.; Investigation, S.M.; Resources, S.M.; Data Curation, S.M.; Writing-Original Draft Preparation, S.M.; Writing-Review \& Editing, S.M. and I.L.; Visualization, S.M.; Supervision, S.M.; Project Administration, S.M.; Funding Acquisition, S.M.

Funding: This work was funded by the Pathaphid project (CY 3526/177 S.M.) of the "Research and Technological Development Innovation Projects (MER) MIS 453350, under the OP HUMAN RESOURCES DEVELOPMENT (RENADE, NSRF 2007-2013)"; the European Social Fund (ESF); National Resources (NSRF 2007-2014); and it was coordinated by ELGO-Demeter.

Acknowledgments: We would like to thank Ioanna Zampara, MA in Interpreting and Translating, for her linguistic input. We would also like to thank the Benaki Phytopathological Institute, Athens, for providing us with the G. mellonella larvae.

Conflicts of Interest: The authors declare no conflict of interest.

\section{References}

1. Vega, F.E.; Goettel, M.S.; Blackwell, M.; Chandler, D.; Jackson, M.A.; Keller, S.; Koike, M.; Maniania, N.K.; Monzón, A.; Ownley, B.H.; et al. Fungal entomopathogens: New insights on their ecology. Fungal Ecol. 2009, 2,149-159. [CrossRef]

2. Mantzoukas, S.; Chondrogiannis, C.; Grammatikopoulos, G. Effects of three endophytic entomopathogens on sweet sorghum and on the larvae of the stalk borer Sesamia nonagrioides. Entomol. Exp. Appl. 2015, 154, 78-87. [CrossRef]

3. Vidal, S.; Jaber, L.R. Entomopathogenic fungi as endophytes: Plant-endophyte-herbivore interactions and prospects for use in biological control. Curr. Sci. 2015, 109, 46-54.

4. Akello, J.; Dubois, T.; Coyne, D.; Kyamanywa, S. Effect of endophytic Beauveria bassiana on populations of the banana weevil, Cosmopolites sordidus, and their damage in tissue-cultured banana plants. Entomol. Exp. Appl. 2008, 129, 157-165. [CrossRef]

5. Carroll, G. Fungal Endophytes in Stems and Leaves: From Latent Pathogen to Mutualistic Symbiont. Ecology 1988, 69, 2-9. [CrossRef]

6. Kannadan, S.; Rudgers, J.A. Endophyte symbiosis benefits a rare grass under low water availability. Funct. Ecol. 2008, 22, 706-713. [CrossRef]

7. Zimmermann, G. The 'Galleria bait method' for detection of entomopathogenic fungi in soil. J. Appl. Entomol. 1986, 102, 213-215. [CrossRef]

8. McKinnon, A.C.; Saari, S.; Moran-Diez, M.E.; Meyling, N.V.; Raad, M.; Glare, T.R. Beauveria bassiana as an endophyte: A critical review on associated methodology and biocontrol potential. BioControl 2017, 62, 1-17. [CrossRef]

9. Bing, L.A.; Lewis, L.C. Temporal relationships between Zea mays, Ostrinia nubilalis (Lep.: Pyralidae) and endophytic Beauveria bassiana. Entomophaga 1992, 37, 525-536. [CrossRef]

10. Bing, L.A.; Lewis, L.C. Endophytic Beauveria bassiana (balsamo) vuillemin in corn: The influence of the plant growth stage and Ostrinia nubilalis (hübner). Biocontrol Sci. Technol. 1992, 2, 39-47. [CrossRef]

11. Wagner, B.L.; Lewis, L.C. Colonization of corn, Zea mays, by the entomopathogenic fungus Beauveria bassiana. Appl. Environ. Microbiol. 2000, 66, 3468-3473. [CrossRef]

12. Yan, J.F.; Broughton, S.J.; Yang, S.L.; Gange, A.C. Do endophytic fungi grow through their hosts systemically? Fungal Ecol. 2015, 13, 53-59. [CrossRef]

13. Eastop, V.F. Worlwide Importance of Aphids as Virus Vectors. In Aphids as Virus Vectors; Harris, K.F., Maramorosch, K., Eds.; Academic Press: New York, NY, USA, 1977; pp. 3-62.

14. Manoussopoulos, Y.; Mantzoukas, S.; Lagoyiannis, I.; Goudoudaki, S. Colonization of pepper by three entomopathogenic fungi and effect on the probing behavior of green peach aphid. In Proceedings of the XVIth EUCARPIA Capsicum and Eggplant Working Group Meeting in Memoriam Dr. Alain Palloix, Kecskemét, Hungary, 12-14 September 2016; pp. 364-368. 
15. Goettel, M.S.; Inglis, G.D. Fungi: Hyphomycetes. In Manual of Techniques in Insect Pathology; Lacey, L.A., Ed.; Academic Press: San Diego, CA, USA, 1997; pp. 213-249.

16. Quesada-Moraga, E.; Navas-Cortes, J.A.; Maranhao, A.A.; Ortiz-Urquiza, A.; Santiago-Alvarez, C. Factors affecting the occurrence and distribution of entomopathogenic fungi in natural and cultivated soils. Mycol. Res. 2007, 111, 947-966. [CrossRef] [PubMed]

17. Gurulingappa, P.; Sword, G.A.; Murdoch, G.; McGee, P.A. Colonization of crop plants by fungal entomopathogens and their effects on two insect pests when in planta. Biol. Control 2010, 55, 34-41. [CrossRef]

18. Rodriguez, R.J.; White, J.F., Jr.; Arnold, A.E.; Redman, R.S. Fungal endophytes: Diversity and functional roles. New Phytol. 2009, 182, 314-330. [CrossRef] [PubMed]

19. Rogers, S.O.; Bendich, A.J. Extraction of DNA from milligram amounts of fresh, herbarium and mummified plant tissues. Plant Mol. Biol. 1985, 5, 69-76. [CrossRef]

20. Abbott, W.S. A Method of Computing the Effectiveness of an Insecticide. J. Econ. Entomol. 1925, 18, $265-267$. [CrossRef]

21. Ownley, B.H.; Griffin, M.R.; Klingeman, W.E.; Gwinn, K.D.; Moulton, J.K.; Pereira, R.M. Beauveria bassiana: Endophytic colonization and plant disease control. J. Invertebr. Pathol. 2008, 98, 267-270. [CrossRef]

22. Ownley, B.H.; Gwinn, K.D.; Vega, F.E. Endophytic fungal entomopathogens with activity against plant pathogens: Ecology and evolution. BioControl 2010, 55, 113-128. [CrossRef]

23. Akello, J.; Sikora, R. Systemic acropedal influence of endophyte seed treatment on Acyrthosiphon pisum and Aphis fabae offspring development and reproductive fitness. Biol. Control. 2012, 61, 215-221. [CrossRef]

24. Pelizza, S.A.; Mariottini, Y.; Russo, L.M.; Vianna, M.F.; Scorsetti, A.C.; Lange, C.E. Beauveria bassiana (Ascomycota: Hypocreales) introduced as an endophyte in corn plants and its effects on consumption, reproductive capacity, and food preference of Dichroplus maculipennis (Orthoptera: Acrididae: Melanoplinae). J. Insect Sci. 2017, 17, 1-6. [CrossRef]

25. Jaber, L.R.; Vidal, S. Fungal endophyte negative effects on herbivory are enhanced on intact plants and maintained in a subsequent generation. Ecol. Entomol. 2010, 35, 25-36. [CrossRef]

26. Kuldau, G.; Bacon, C. Clavicipitaceous endophytes: Their ability to enhance resistance of grasses to multiple stresses. Biol. Control 2008, 46, 57-71. [CrossRef]

27. Lopez, C.D.; Zhu-Salzman, K.; Ek-Ramos, J.M.; Sword, G.A. The Entomopathogenic Fungal Endophytes Purpureocillium lilacinum (Formerly Paecilomyces lilacinus) and Beauveria bassiana Negatively Affect Cotton Aphid Reproduction under Both Greenhouse and Field Conditions. PLoS ONE 2014, 9, e103891.

28. Bing, L.A.; Lewis, L.C. Suppression of Ostrinia nubilalis (Hübner) (Lepidoptera: Pyralidae) by endophytic Beauveria bassiana (Balsamo) Vuillemin. Environ. Entomol. 1991, 20, 1207-1211. [CrossRef]

29. Posada, F.; Vega, F.E. Establishment of the fungal entomopathogen Beauveria bassiana (Ascomycota: Hypocreales) as an endophyte in cocoa seedlings (Theobroma cacao). Mycologia 2005, 97, 1195-1200. [CrossRef] [PubMed]

30. Posada, F.; Vega, F.E. Inoculation and colonization of coffee seedlings (Coffea arabica L.) with the fungal entomopathogen Beauveria bassiana (Ascomycota: Hypocreales). Mycoscience 2006, 47, 284-289. [CrossRef]

31. Gómez-Vidal, S.; Lopez-Llorca, L.V.; Jansson, H.-B.; Salinas, J. Endophytic colonization of date palm (Phoenix dactylifera L.) leaves by entomopathogenic fungi. Micron 2006, 37, 624-632.

32. Tefera, T.; Vidal, S. Effect of inoculation method and plant growth medium on endophytic colonization of sorghum by the entomopathogenic fungus Beauveria bassiana. BioControl 2009, 54, 663-669. [CrossRef]

33. Arab, Y.A.; El-Deeb, H.M. The use of endophyte Beauveria bassiana for bio-protection of date palm seedlings against red palm weevil and rhizoctonia root-rot disease. Sci. J. King Faisal Univ. (Basic Appl. Sci.) 2012, 13, 91-101.

34. Batta, Y.A. Efficacy of endophytic and applied Metarhizium anisopliae (Metch.) Sorokin (Ascomycota: Hypocreales) against larvae of Plutella xylostella L. (Yponomeutidae: Lepidoptera) infesting Brassica napus plants. Crop Prot. 2013, 44, 128-134. [CrossRef]

35. Landa, B.B.; López-Díaz, C.; Jiménez-Fernández, D.; Montes-Borrego, M.; Muñoz-Ledesma, F.J.; Ortiz-Urquiza, A.; Quesada-Moraga, E. In-planta detection and monitorization of endophytic colonization by a Beauveria bassiana strain using a new-developed nested and quantitative PCR-based assay and confocal laser scanning microscopy. J. Invertebr. Pathol. 2013, 114, 128-138. [CrossRef] [PubMed] 
36. Ramirez-Rodriguez, D.; Sánchez-Peña, S.R. Endophytic Beauveria bassiana in Zea mays: Pathogenicity against Larvae of Fall Armyworm, Spodoptera frugiperda. Southwest. Entomol. 2016, 41, 875-878. [CrossRef]

37. Ramírez-Rodríguez, D.; Sánchez-Peña, S.R. Recovery of endophytic Beauveria bassiana on a culture medium based on cetyltrimethylammonium bromide. Biocontrol Sci. Technol. 2016, 26, 570-575. [CrossRef]

38. Jaber, L.R.; Araj, S.-E. Interactions among endophytic fungal entomopathogens (Ascomycota: Hypocreales), the green peach aphid Myzus persicae Sulzer (Homoptera: Aphididae), and the aphid endoparasitoid Aphidius colemani Viereck (Hymenoptera: Braconidae). Biol. Control. 2018, 116, 53-61. [CrossRef]

39. Powell, W.A.; Klingeman, W.E.; Ownley, B.H.; Gwinn, K.D. Evidence of Endophytic Beauveria bassiana in Seed-treated Tomato Plants Acting as a Systemic Entomopathogen to Larval Helicoverpa zea (Lepidoptera: Noctuidae). J. Entomol. Sci. 2009, 44, 391-396. [CrossRef]

40. Russo, M.L.; Pelizza, S.A.; Vianna, M.F.; Allegrucci, N.; Cabello, M.N.; Toledo, A.V.; Mourelos, C.; Scorsetti, A.C. Effect of endophytic entomopathogenic fungi on soybean Glycine max (L.) Merr. growth and yield. J. King Saud Univ. - Sci. (in press)

41. Griffin, M.R.; Ownley, B.H.; Klingeman, W.E.; Pereira, R.M. Biocontrol of Rhizoctonia damping-off of cotton with endophytic Beauveria bassiana. Phytopathology 2005, 95, S36.

42. Ownley, B.H.; Pereira, R.M.; Klingeman, W.E.; Quigley, N.B.; Leckie, B.M. Beauveria bassiana, a dual purpose biocontrol organism, with activity against insect pests and plant pathogens. In Emerging Concepts in Plant Health Management; Lartey, R.T., Cesar, A.J., Eds.; Research Signpost: Thiruvananthapuram, India, 2004; pp. 255-269.

43. Lopez, D.C.; Sword, G.A. The endophytic fungal entomopathogens Beauveria bassiana and Purpureocillium lilacinum enhance the growth of cultivated cotton (Gossypium hirsutum) and negatively affect survival of the cotton bollworm (Helicoverpa zea). Biol. Control 2015, 89, 53-60. [CrossRef]

44. Greenfield, M.; Gómez-Jiménez, M.I.; Ortiz, V.; Vega, F.E.; Kramer, M.; Parsa, S. Beauveria bassiana and Metarhizium anisopliae endophytically colonize cassava roots following soil drench inoculation. Biol. Control 2016, 95, 40-48. [CrossRef]

45. Qayyum, M.A.; Wakil, W.; Arif, M.J.; Sahi, S.T.; Dunlap, C.A. Infection of Helicoverpa armigera by endophytic Beauveria bassiana colonizing tomato plants. Biol. Control 2015, 90, 200-207. [CrossRef]

(C) 2019 by the authors. Licensee MDPI, Basel, Switzerland. This article is an open access article distributed under the terms and conditions of the Creative Commons Attribution (CC BY) license (http://creativecommons.org/licenses/by/4.0/). 